\title{
Corrigendum
}

\section{Corrigendum to “Chitosan Prevents Gentamicin-Induced Nephrotoxicity via a Carbonyl Stress-Dependent Pathway"}

\author{
Chu-Kuang Chou, ${ }^{1,2}$ Yi-Chieh Li, ${ }^{3}$ Shih-Ming Chen, ${ }^{3}$ Yi-Min Shih, ${ }^{3}$ and Jen-Ai Lee ${ }^{3}$ \\ ${ }^{1}$ Department of Internal Medicine, Chia-Yi Christian Hospital, 539 Jhongsiao Road, Chiayi City 60002, Taiwan \\ ${ }^{2}$ Department of Internal Medicine, National Taiwan University Hospital, No. 7, Chung-Shan South Road, Taipei City 10002, Taiwan \\ ${ }^{3}$ School of Pharmacy, College of Pharmacy, Taipei Medical University, 250 Wuxing Street, Taipei City 11031, Taiwan
}

Correspondence should be addressed to Jen-Ai Lee; jenai@tmu.edu.tw

Received 13 August 2017; Accepted 17 August 2017; Published 24 September 2017

Copyright (c) 2017 Chu-Kuang Chou et al. This is an open access article distributed under the Creative Commons Attribution License, which permits unrestricted use, distribution, and reproduction in any medium, provided the original work is properly cited.

In the article titled "Chitosan Prevents Gentamicin-Induced Nephrotoxicity via a Carbonyl Stress-Dependent Pathway” [1], the name of the first author was given incorrectly as ChuKung Chou. The author's name should have been written as Chu-Kuang Chou. The revised authors' list is shown above.

Also, there was an error in Figure 2. Figures 2(b) and $2(\mathrm{e})$ were inadvertently reused from $\mathrm{Yi}-\mathrm{Chieh} \mathrm{Li}$,
Yi-Min Shih, and Jen-Ai Lee, "Gentamicin caused renal injury deeply related to methylglyoxal and $\mathrm{N} \varepsilon$-(carboxyethyl)lysine (CEL)," Toxicology Letters, Volume 219, Issue 1, https://www.doi.org/10.1016/j.toxlet.2013.01.024. Additionally, the same picture of Figure 2(e) was presented as Figure 2 (c). The corrected Figure 2 is as follows.

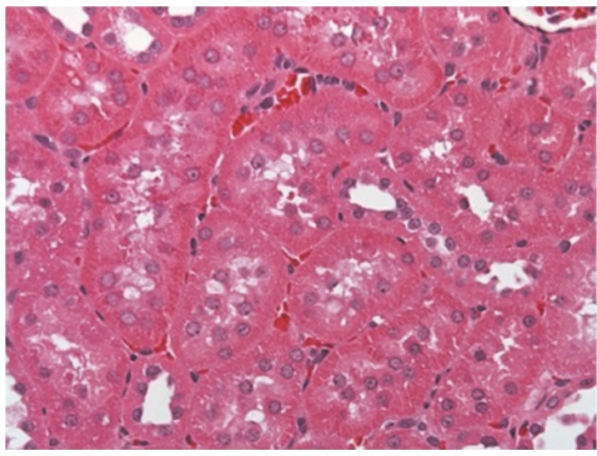

(a)

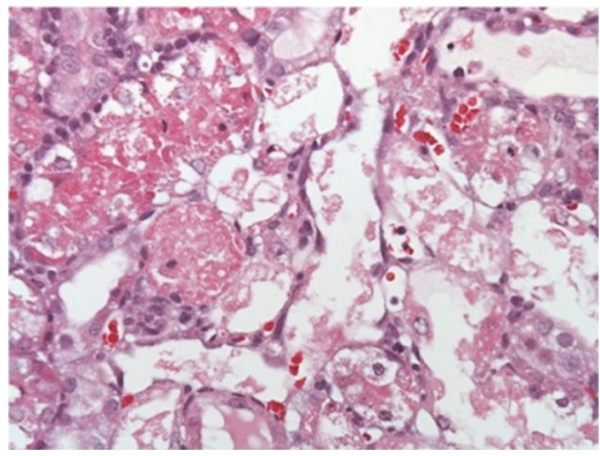

(b)

FIgure 2: Continued. 


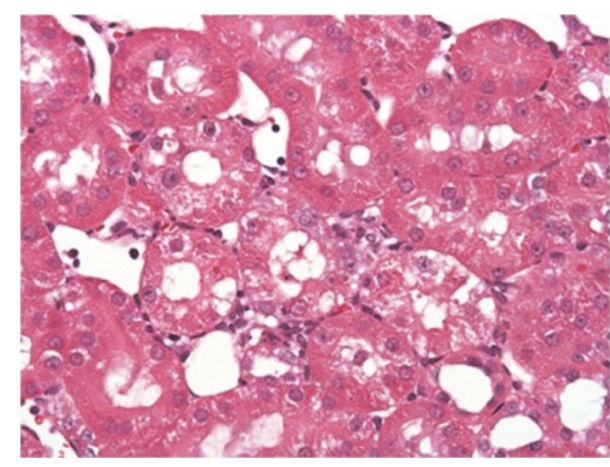

(c)

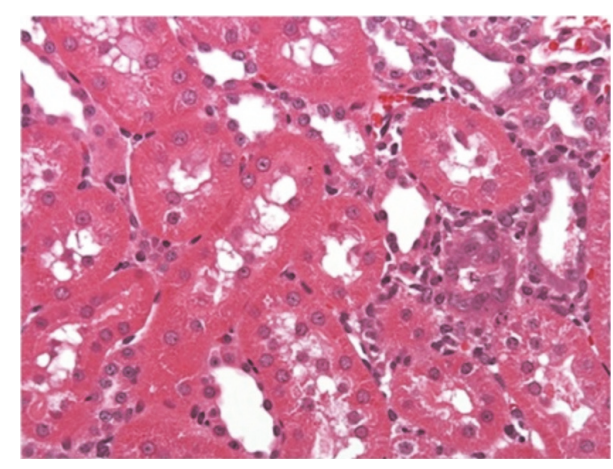

(d)

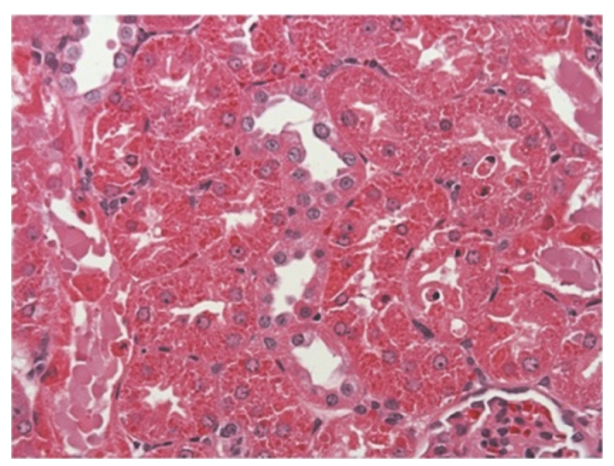

(e)

FIGURE 2: LMWC-induced changes in histology. Light micrographs of rat kidney sections were stained with hematoxylin and eosin. (a) Histology of kidney tissue in the control group. (b) Necrotic tubules and desquamation were apparent after treatment with $150 \mathrm{mg} / \mathrm{kg} / \mathrm{day} \mathrm{GM}$ for 6 days. (c) Treatment of GN rats with $165 \mathrm{mg} / \mathrm{kg} /$ day LMWC for 13 days improved histology. (d) Treatment of GN rats with $825 \mathrm{mg} / \mathrm{kg} / \mathrm{day}$ LMWC for 13 days significantly improved histology. (e) Treatment of GN rats with $100 \mathrm{mg} / \mathrm{kg} /$ day metformin for 13 days significantly improved histology.

\section{References}

[1] C.-K. Chou, Y.-C. Li, S.-M. Chen, Y.-M. Shih, and J.-A. Lee, "Chitosan prevents gentamicin-induced nephrotoxicity via a carbonyl stress-dependent pathway," BioMed Research International, vol. 2015, Article ID 675714, 8 pages, 2015. 

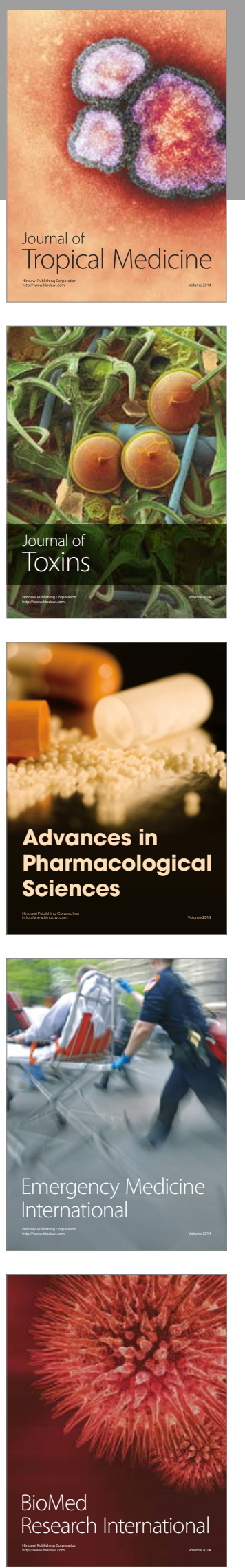
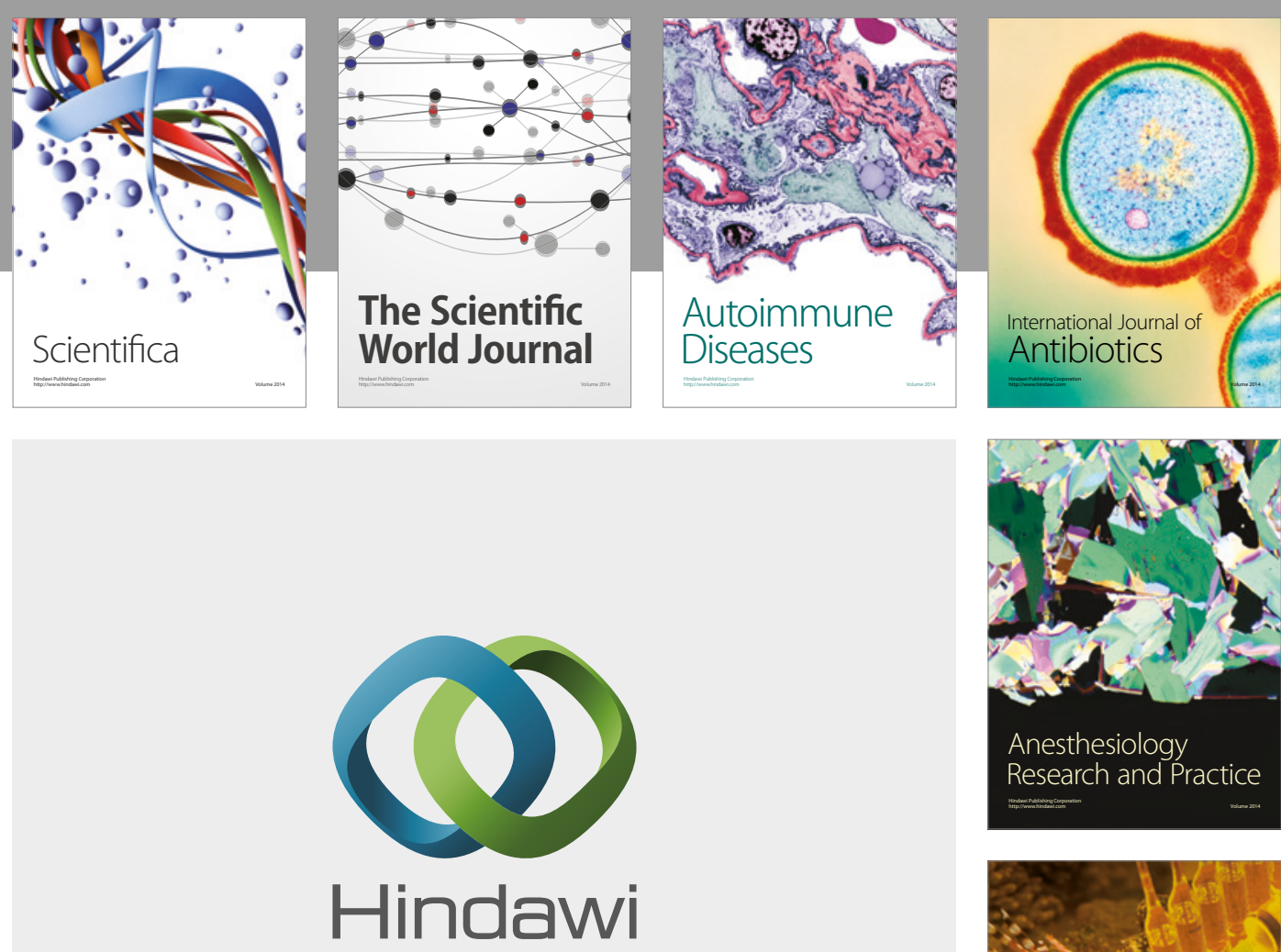

Submit your manuscripts at

https://www.hindawi.com
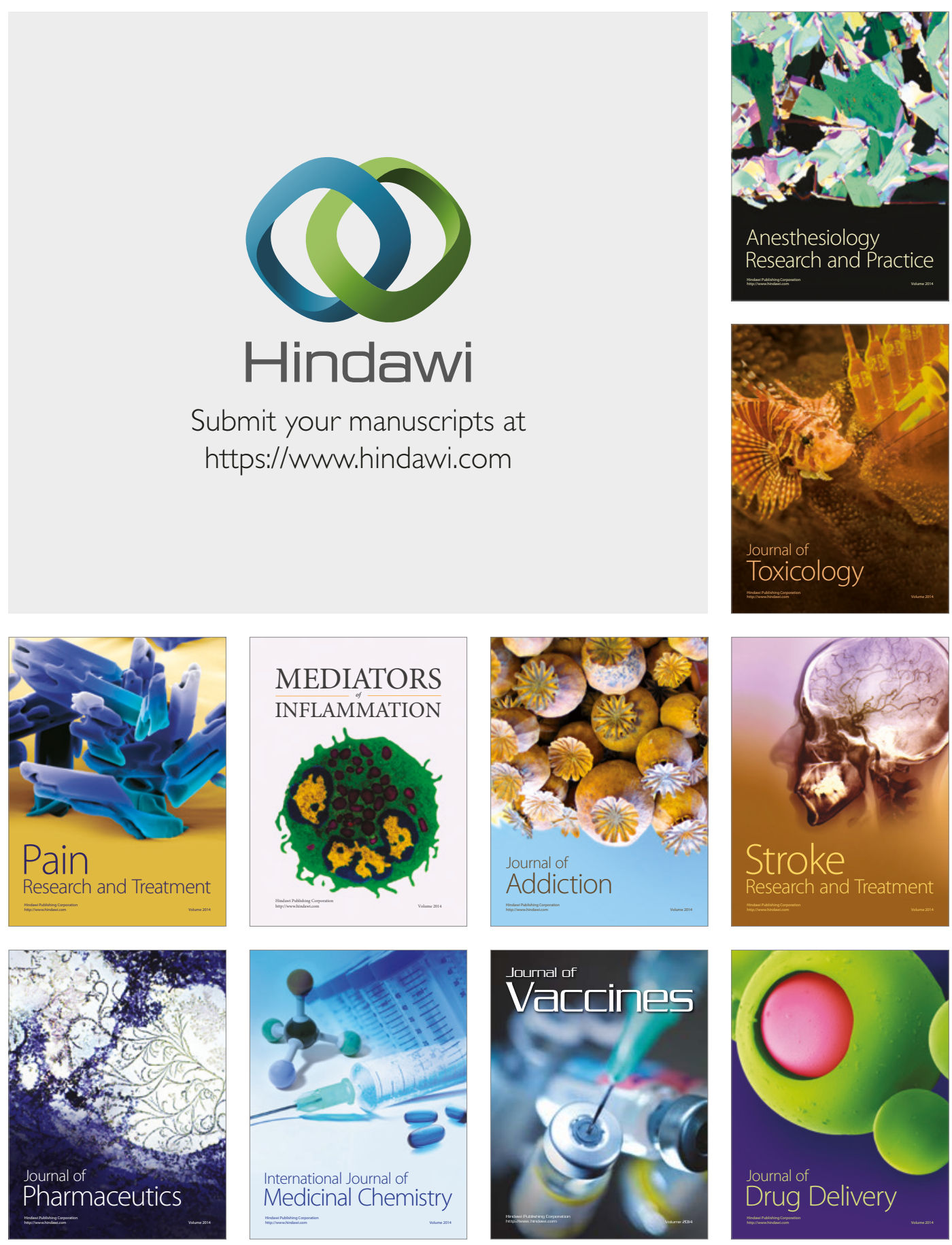